Intecoms: Journal of Information Technology and Computer Science

Volume 1 Nomor 1, Juni 2018

e-ISSN : 2614-1574

p-ISSN : 2621-3249

DOI : https://doi.org/10.31539/intecoms.v1i1.140

\title{
APLIKASI PENGOLAHAN DATA SURAT IZIN USAHA ANGKUTAN BARANG PADA KANTOR DINAS PERHUBUNGAN KABUPATEN LIMAPULUH
}

\section{APPLICATION OF DATA PROCESSING LICENSE FOR GOODS TRANSPORTATION AT THE OFFICE OF TRANSPORTATION OF LIMAPULUH REGENCY}

\author{
Irohito Nozomi ${ }^{1}$,Muhammad Lutfi Hamzah ${ }^{2}$ \\ Universitas Putra Indonesia "YPTK" 1 \\ STIKOM Pelita Indonesia ${ }^{2}$ \\ irohitonozomi@gmail.com ${ }^{1}$
}

\begin{abstract}
The ability and speed of computers in processing data repeatedly and with a very large number is no doubt to produce the reports needed in the process of strategic decision-making. So at this time has been many companies and government agencies want to use computer technology to help solve their data processing problems. In the Office of Transportation (DISHUB) of Kabupaten Lima Puluh Kota, the data processing business licenses have been conducted frequently, but have not obtained accurate results. This is due to the use of information technology is still very less and implemented manually. The accuracy of the data is necessary to avoid irregularities and errors in reports. Application System will be proposed later using PHP programming language and MYSQL. All data entry will be processed in a Database. Diverse data will be more easily and quickly processed in a well-structured system.
\end{abstract}

Keywords :Data Processing, PHP, MYSQL

\begin{abstract}
ABSTRAK
Kemampuan dan kecepatan komputer dalam mengolah data yang berulang-ulang dan dengan jumlah yang sangat besar sudah tidak diragukan lagi untuk menghasilkan laporan-laporan yang dibutuhkan dalam proses pengambilan keputusan strategis. Sehingga pada saat sekarang ini telah banyak perusahaan maupun instansi pemerintah mau meggunakan teknologi komputer guna membantu pemecahan masalah pengolahan data mereka. Pada Kantor Dinas Perhubungan (DISHUB) Kabupaten Lima Puluh Kota proses pengolahan data surat izin usaha angkutan barang telah sering dilakukan, namun belum memperoleh hasil yang akurat. Hal ini disebabkan penggunaan teknologi informasi masih sangat kurang dan dilaksanakan secara manual. Keakuratan data sangat diperlukan agar tidak terjadi penyimpangan serta kesalahan dalam laporan-laporannya. Sistem Aplikasi yang akan diusulkan nantinya menggunakan bahasa pemograman PHP da MYSQL. Semua entry data tersebut akan diolah dalam sebuah basis data. Data beraneka ragam itu akan semakin mudah dan cepat diolah dalam sebuah sistem yang tersusun dengan baik.
\end{abstract}

Kata Kunci : Pengolahan data, PHP, MYSQL 


\section{PENDAHULUAN}

Pada Kantor Dinas Perhubungan (DISHUB) Kabupaten Lima Puluh Kota proses pengolahan data surat izin usaha angkutan barang telah sering dilakukan, namun belum memperoleh hasil yang akurat. Hal ini disebabkan penggunaan teknologi informasi masih sangat kurang. Keakuratan data sangat diperlukan agar tidak terjadi penyimpangan serta kesalahan dalam laporan-laporannya.

Dengan pengolahan data secara komputerisasi diharapkan dapat mengatasi permasalahan dan proses kerja akan lebih cepat serta informasi yang dihasilkan akan lebih memuaskan serta tepat sasaran.

Penelitian terdahulu telah melakukan penelitian tentang pengolahan data seperti Asynuzar (2014) mengembangkan aplikasi tentang pengolahan data cuaca pada statiun meteorologi Maritim Pontianak yang terbukti dapat membantu petugas dalam pengolahan data dengan cepat, praktis, dan efisien. Kemudian Khambali et. al. (2017) juga membangun aplikasi pengolahan data unsur cuaca pada statiun Meteorologi kota Tegal dengan menggunakan model Waterfall.

Arman (2016) mengembangkan sistem informasi terkait pengolahan data penduduk Nagari Tanjung Lolo berbasis web dan di Kantor Kecamatan Sungai Selan Bangka Tengah (Lestari, 2015) yang dapat memberikan kemudahan bagi pengguna dan masyarakat dalam mendapatkan informasi dan mendapatkan surat yang cepat dan efisien. Musliani et. al. (2017) juga mengembangkan aplikasi pengolahan data posyandu untuk membantu pihak Posyandu dalam melaporkan kegiatan pelayanan terhadap bayi dan ibu hamil. Dan Tiningsih (2011) juga mengembangkan sistem infomasi pengolahan data perpustakaan pada SMK Negeri 1 Demak tentang pengolahan data anggota, data buku, peminjaman, pengembalian dan denda.

Kemudian Fajri dan Iswandy (2017) mengembangkan sistem informasi pengolahan data laporan statistik pertaninan tanaman pangan di Koto Gadih Payakumbuh dan Hamzah (2016) juga membangun sistem pengolahan data kegiatan Penelitian dan Pengabdian kepada masyarakat di Universitas Respati Yogyakarta yang membantu unit penelitian dan pengabdian pada masyarakat dalam proses pengolahan data rekam jejak kegiatan peneltian dan kegiatan pada masyarakat yang dilakukan dosen.

\section{METODE PENELITIAN Data Penelitian}

Data-data penelitian merupakan data-data terkait data surat izin usaha angkutan barang pada kantor Dinas Perhubungan Kabupaten Lima Puluh Kota. Data penelitian diambil dengan melakukan observasi pada kantor tersebut dan dengan melakukan wawancara terkait pengolahan data surat izin angkutan barang. Kemudian peneliti melakukan studi literatur untuk mendukung literatur penelitian agar hasilnya sesuai dengan yang diharapkan.

\section{Tools yang Digunakan}

Penelitian ini dalam pembuatan sistemnya menggunakan software notepad++ untuk bahasa pemograman PHP, dan MYSQL sebagai tempat penyimpanan data yang akan digunakan.

\section{Metode Pengembangan Sistem}

Dalam pengembangan sistem pengolahan data surat izin angkutan barang ini menggunakan metode waterfall yang bekerja dengan 
sistematis dan terstuktur secara bertahap dalam pembangunan sistem.

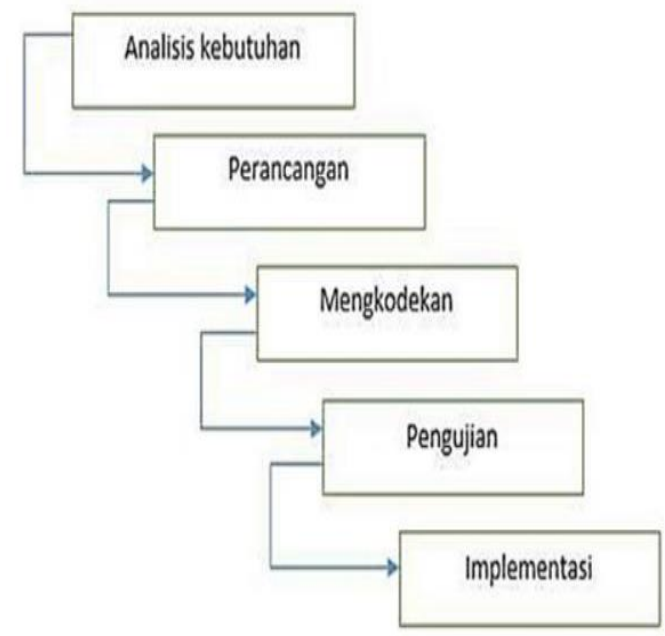

Gambar 1. Model Waterfall

Pada gambar diatas adalah tahapan-tahapan dalam mengembangan sistem pengolahan data surat izin angkutan barang. Adapun langkahlangkah nya adalah :

Analisis Kebutuhan : Langkah awal yang harus dilakukan yaitu menidentifikasi kebutuhan-kebutuhan apa saja yang dibutuhkan dalam membangun suatu sistem pengolahan data surat izin angkutang barang dengan cara melakukan observasi dan wawancara.

Perancangan : Langkah yang kedua ini terkait perancangan yang akan dibuat dalam pembangunan sistem sesuai.

Pengkodean : Langkah ke tiga yaitu melakukan pengkodean sistem sesuai dengan perancangan yang dirancang sebelumnya. Pengkodean ini menggunakan bahasa pemograman PHP dan MYSQL untuk penyimpanan data.

Pengujian : Langkah ke empat yatu melakukan test atau pengujian terhadap sistem yang telah dibangun agar sesuai dengan yang diharapkan.

Implementasi : Langkah yang terakhir yaitu penerapan aplikasi pengolahan data surat izin angkutan barang pada kantor Dinas Perhubungan Kabupaten Lima Puluh Kota.

\section{HASIL DAN PEMBAHASAN \\ A. Kebutuhan Sistem}

Untuk

dapat mengimplementasi sistem yang telah dibangun, standar minimal hardware yang dapat digunakan adalah processor intel core i3 dan memory $1 \mathrm{~GB}$.

\section{B. Context Diagram}

Context Diagram merupakan gambaran secara global atau umum dari sistem yang dirancang secara logika tanpa mempertimbangkan lingkungan fisik tempat data itu mengalir atau tempat data itu disimpan. Keuntungan dari context diagram adalah memudahkan pemakai untuk mengerti sistem yang akan dikembangkan. Berikut ini adalah gambar context diagram pada Dinas Perhubungan Kab. Lima Puluh Kota, dapat dilihat pada gambar :

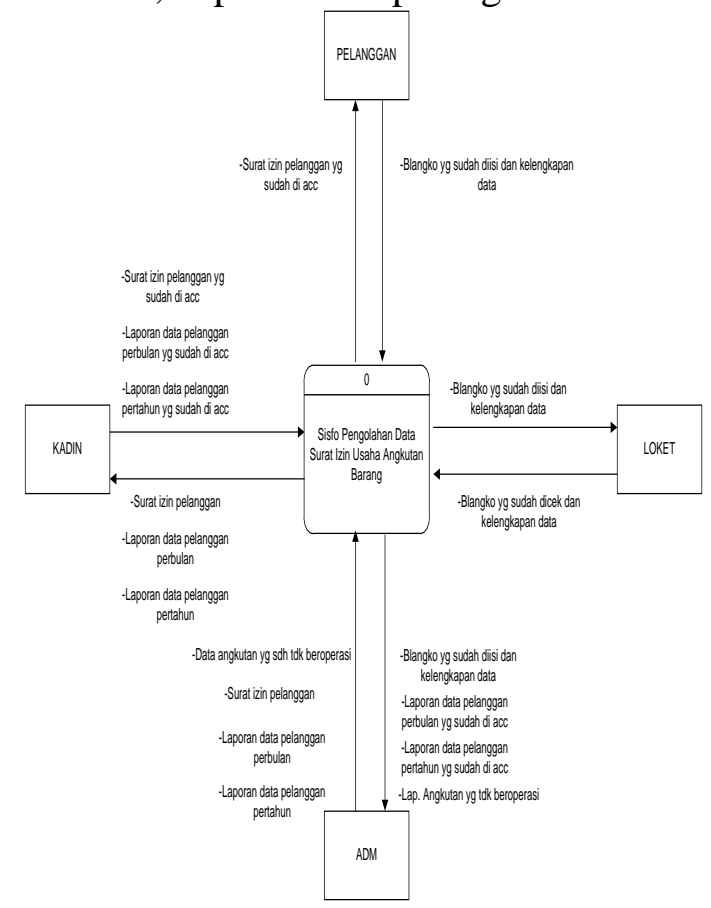

Gambar 2. Context Diagram Pada Dinas Perhubungan Kab. Lima Puluh Kota 


\section{Data Flow Diagram (DFD)}

Data Flow Diagram

digunakan untuk menggambarkan sistem secara logika yang akan menunjukkan bagaimana secara logika fungsi-fungsi sistem informasi akan bekerja. DFD merupakan alat yang digunakan pada metodologi pengembangan sistem yang terstuktur (structure analysis design). DFD level 0 merupakan penjabaran context diagram.

Adapun Data Flow Diagram (DFD) dari sisitem informasi pada Dinas Perhubungan Kab. Lima Puluh Kota adalah seperti terlihat pada gambar berikut:

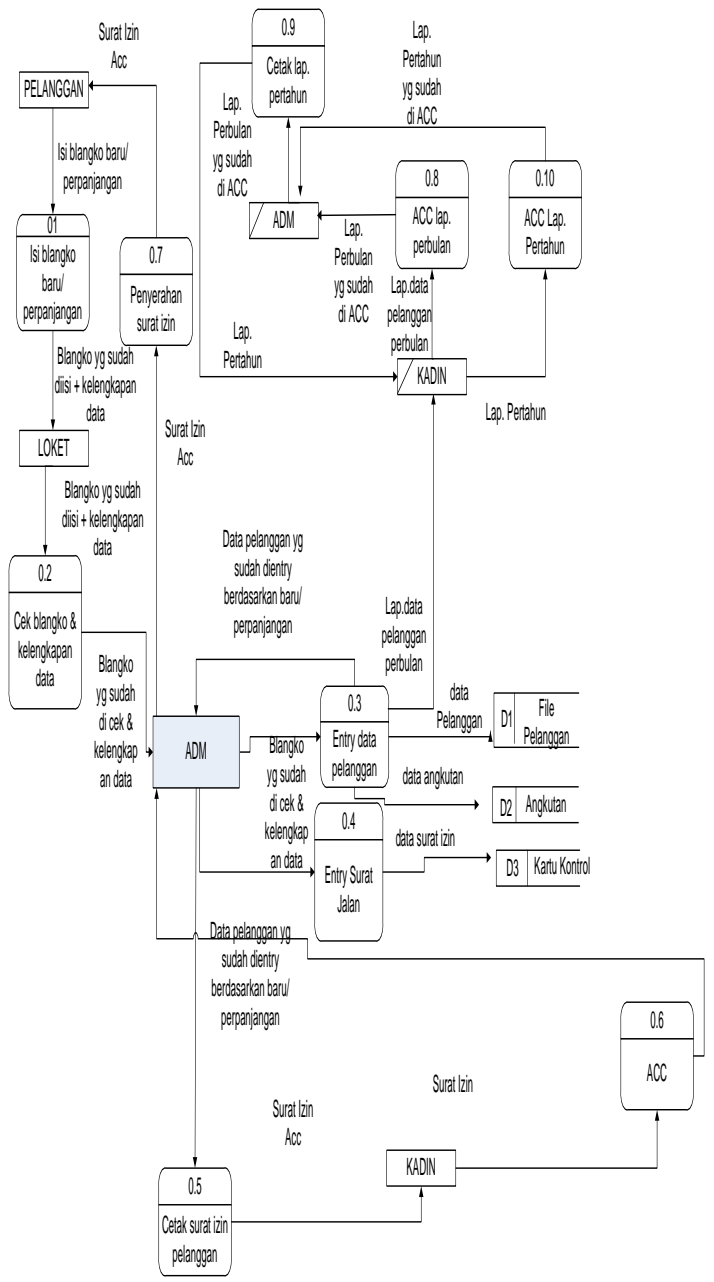

Gambar 3. DFD Pada Dinas Perhubungan Kab. Lima Puluh Kota
D. Entity Relationship Diagram (ERD) Entity Relationship Diagram adalah suatu model jaringan kerja (network) yang menguraikan susunan data yang distore dari sistem secara abstrak. Entity Relationship Diagram menunjukkan hubungan antar entity didalam sistem. Bentuk ERD yang dirancang terlihat dalam gambar berikut :

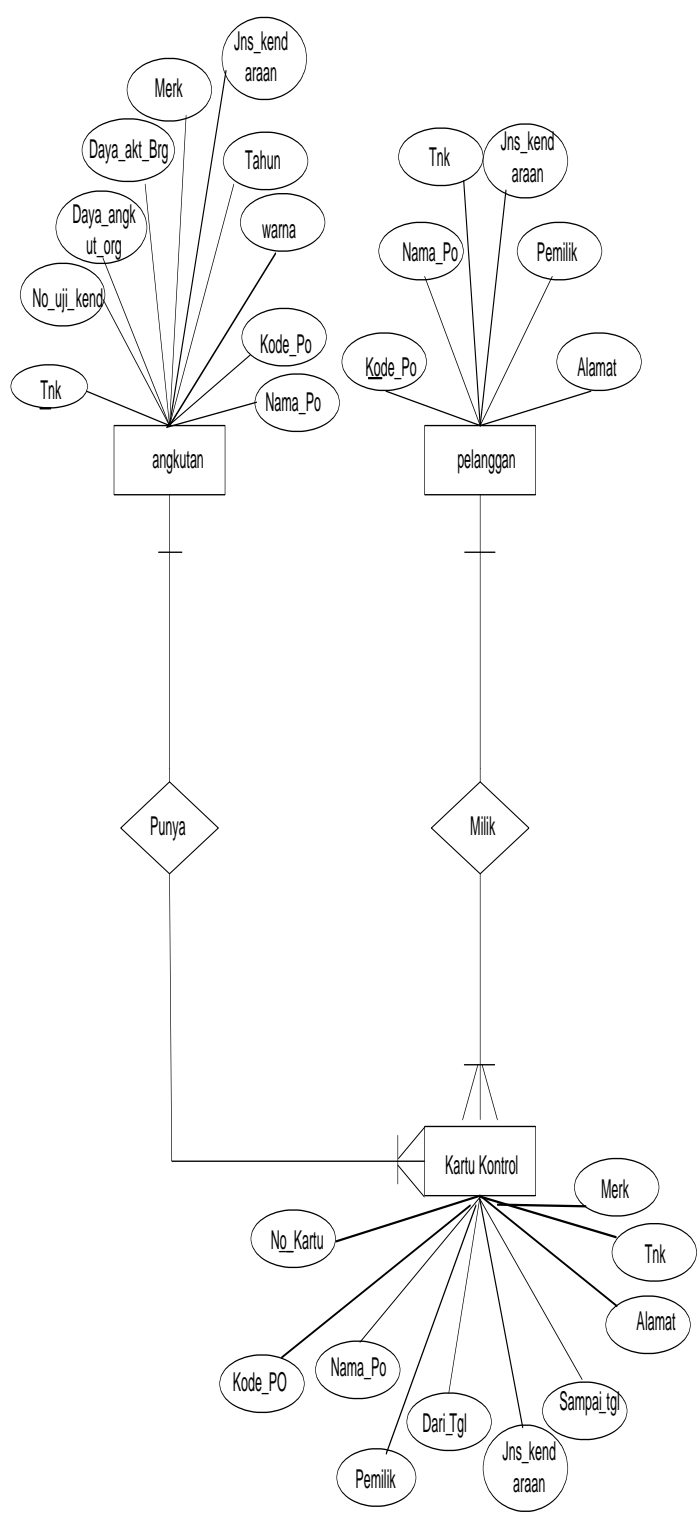

Gambar 4. ERD Pada Dinas Perhubungan Kab. Lima Puluh Kota 


\section{E. Struktur Program}

Struktur Program merupakan gambaran umum dari program yang dirancang oleh penulis, dimana menggambarkan aliran-aliran dan bagian-bagian program yang akan diterapkan pada Dinas Perhubungan Kabupaten Lima Puluh Kota. Disini akan diterapkan suatu program aplikasi yaitu PHP MYSQL yang akan menampilkan laporan yang sudah diinputkan datanya pada program entry dan laporan sehingga akan diperoleh data yang akurat dan benar. Untuk mempelajari hubungan tersebut dapat dilihat pada gambar :

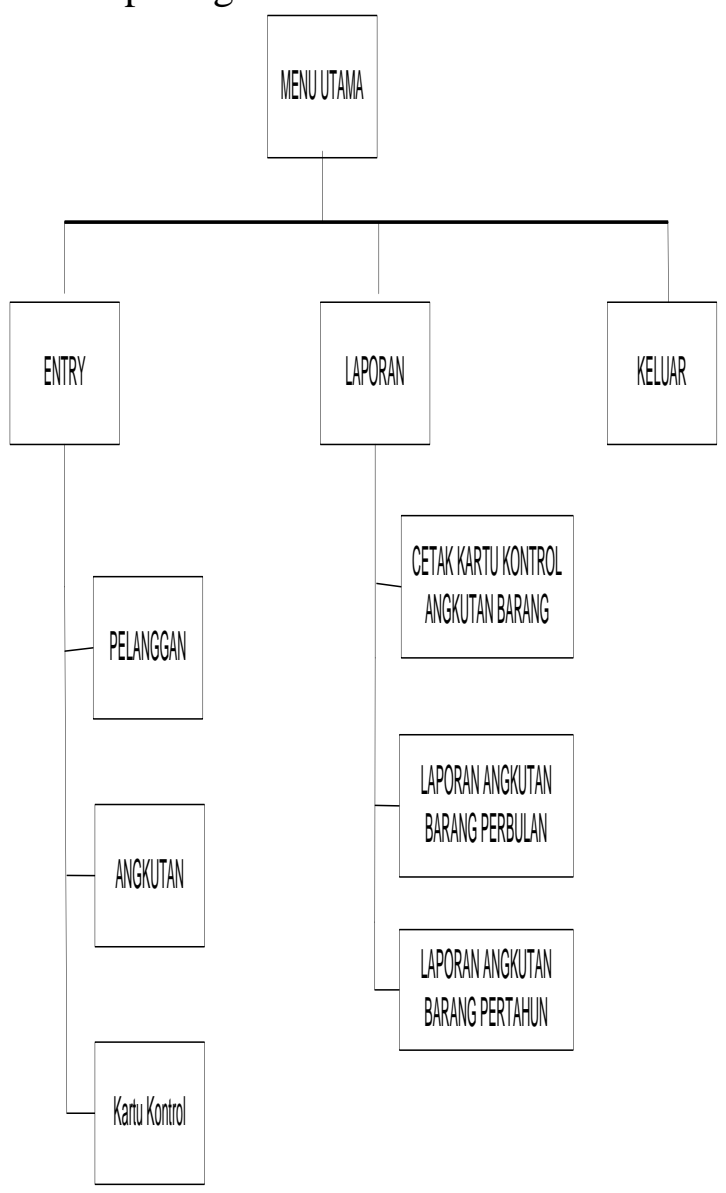

Gambar 5. Struktur Program Pada Dinas Perhubungan Kab. Lima Puluh Kota
F. Implementasi Sistem

1. Login Admin

Dimana admin harus memasukkan Username dan Passoword untuk dapat masuk ke menu utama dari program aplikasi. Seperti yang terlihat pada gambar berikut ini:

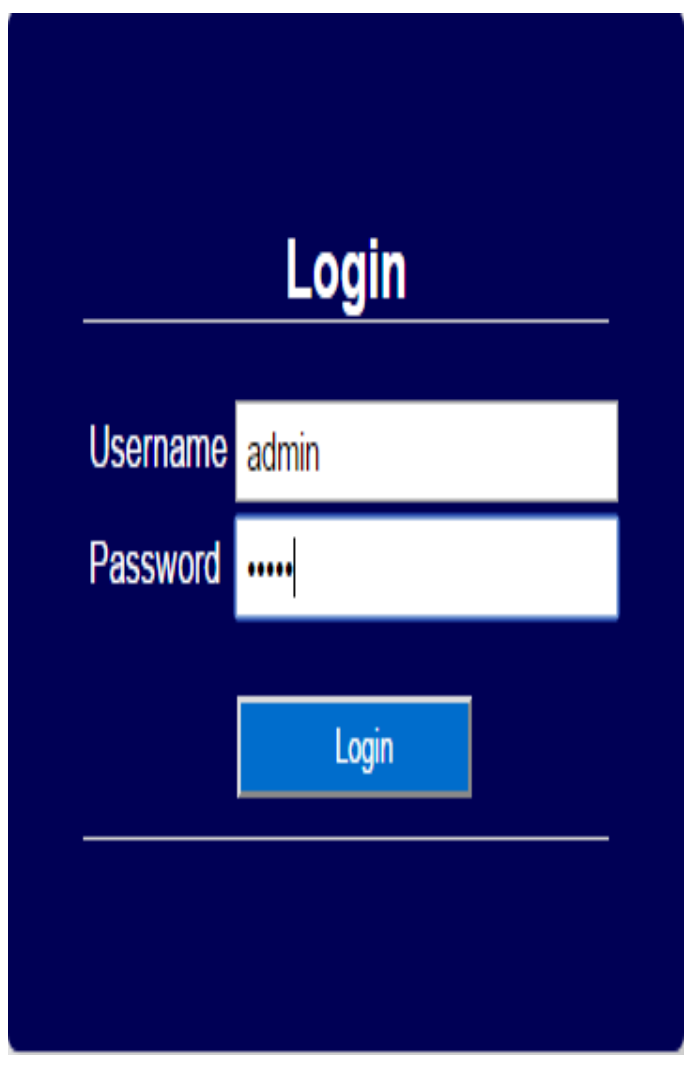

Gambar 6. Tampilan Login

2. Menu Utama

Menu utama menyajikan berbagai pilihan aplikasi yang dapat digunakan untuk mengentrikan data ke dalam database serta mengakses data tersebut kembali untuk dijadikan informasi melalui query yang telah dicodekan dan melalui proses seleksi. Berikut gambar tampilan menu utama,dapat dilihat pada gambar dibawah : 


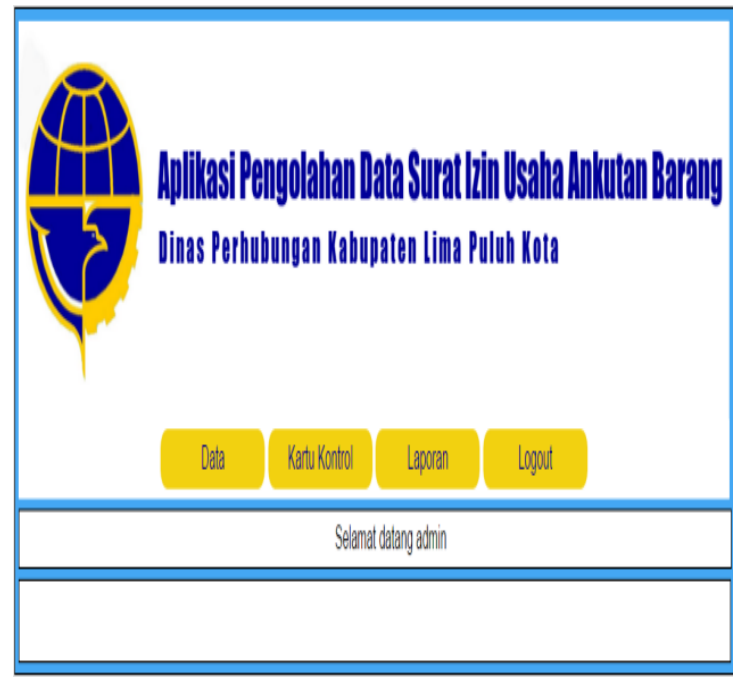

Gambar 7. Tampilan Menu Utama

3. Sub Menu Entry Data

Sub Menu Entry Data merupakan bagian dari Menu Utama. Tampilan dari Sub Menu Entry Data dapat kita lihat pada gambar 5 berikut :

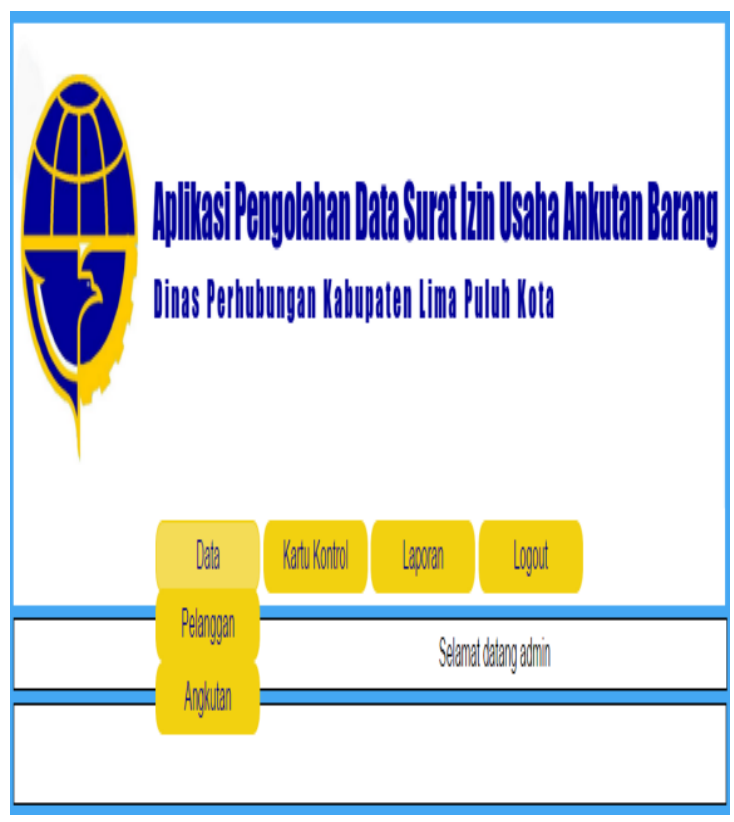

Gambar 8. Tampilan Menu Entry Data

4. Sub Menu Laporan

Dalam Sub Menu ini berisikan tentang laporan perbulan dan pertahun dari angkutan barang yang telah terdaftar.
Seperti yang terlihat pada gambar berikut :

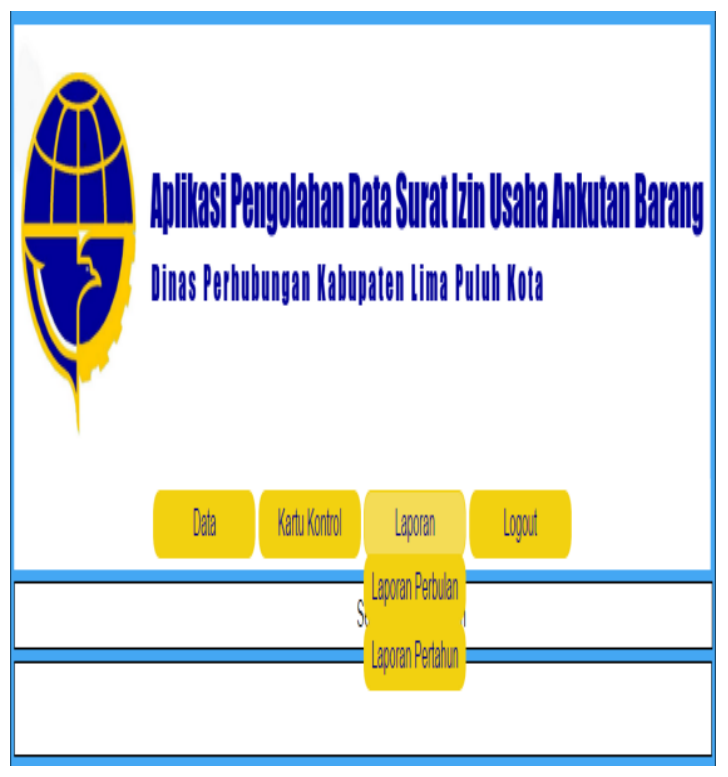

Gambar 9. Tampilan Menu Laporan

5. Sub Menu Entry Data Pelanggan Sub menu entry data Pelanggan adalah tempat pengentryan data pelanggan yang melakukan pembuatan Surat izin (kartu kontrol). Tampilan sub menu entri data pelanggan dapat dilihat pada gambar berikut :

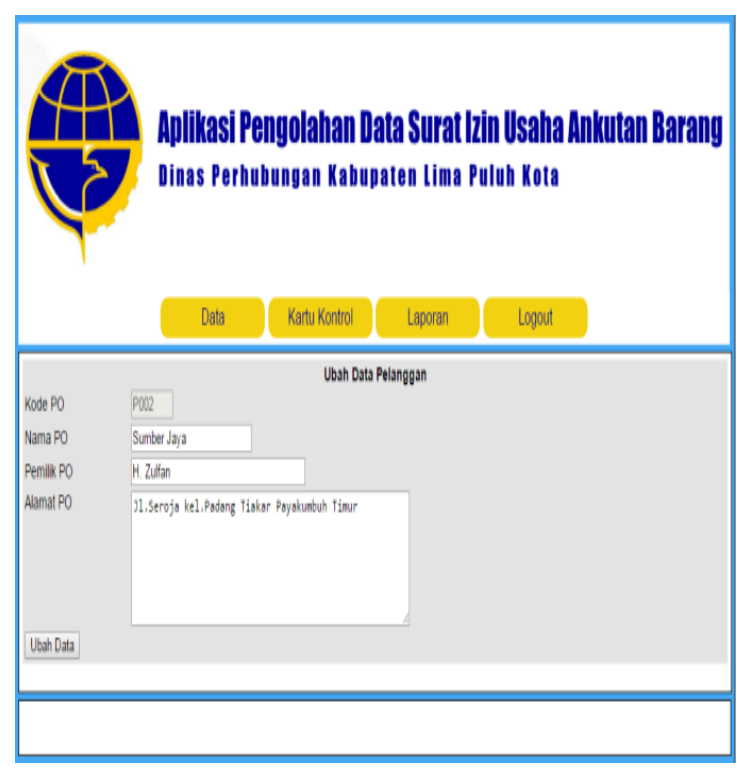

Gambar 10. Tampilan Entry Data Pelanggan 
6. Sub Menu Entry Data Kendaraan

Sub menu entry data kendaraan adalah tempat pengentryan data kendaraan. Tampilan sub menu entry data kendaraan dapat dilihat pada gambar berikut :

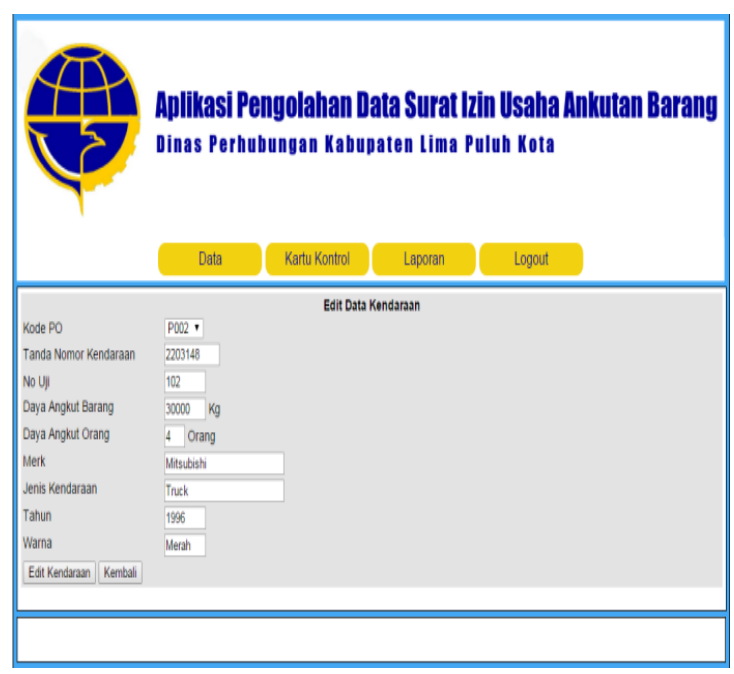

Gambar 11. Tampilan Entry Data

\section{Kendaraan}

7. Preview Laporan Bulanan

Berikut ini adalah preview hasil cetak laporan bulanan angkutan barang. Seperti pada gambar berikut :

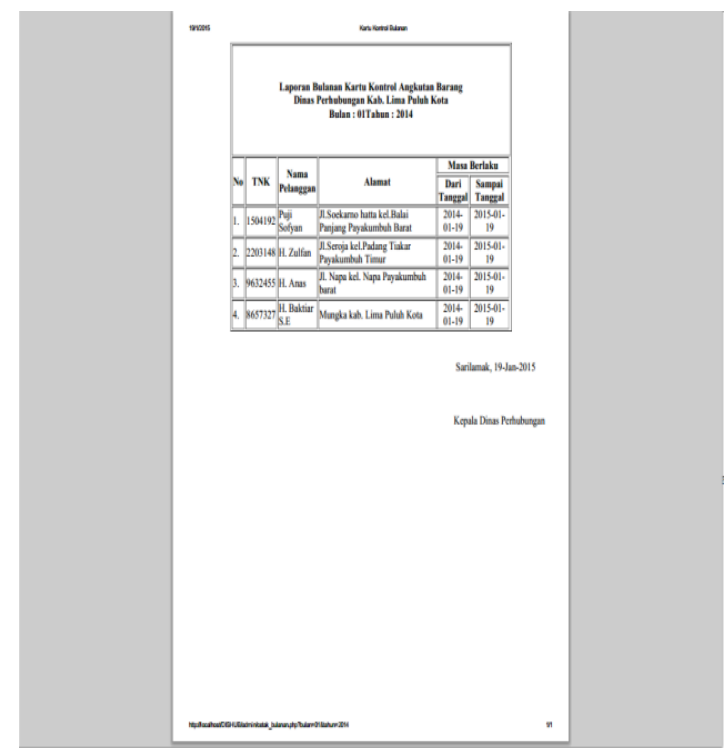

Gambar 12. Preview Laporan Bulanan
8. Laporan Tahunan Angkutan barang

Laporan ini dapat dilihat pada gambar berikut :

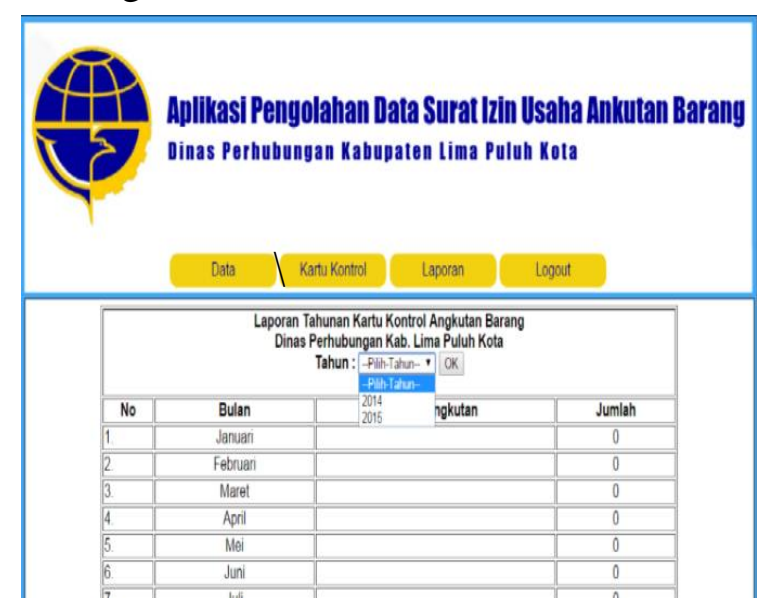

Gambar 13. Tampilan Laporan Tahunan 


\section{SIMPULAN}

Dari uraian dan penjelasan yang telah dikemukakan pada bab-bab sebelumnya, maka dapat ditarik kesimpulan dari penelitian yang telah dilakukan dan saran-saran yang diharapkan bermanfaat bagi pembaca pada umumnya dan bagi pihak yang bersangkutan.Kesimpulan yang dapat dikemukakan antara lain :

1. Bahasa pemrograman PHP MYSQL merupakan salah satu program aplikasi yang digunakan untuk memecahkan permasalahan untuk mempermudah pengolahan data kartu kontrol surat izin usaha angkutan barang pada kantor Dinas Perhubungan Kabupaten Lima Puluh Kota.

2. Keamanan data dapat lebih terjamin dengan menggunakan sebuah database sehingga informasi yang diinginkan dapat diketahui dengan lebih cepat dan akurat bagi pihak yang bersangkutan.

3. Informasi tentang kartu kontrol angkutan barang pada kantor Dinas Perhubungan Kabupaten Lima Puluh Kota dapat diketahui lebih cepat, akurat, dengan penggunaan sistem komputerisasi yang optimal.

4. Sistem yang baru ini dapat meminimalkan waktu dalam proses pembuatan laporan dan laporan yang dihasilkan menjadi lebih efektif dan efisien . 
DAFTAR PUSTAKA

Arman, A. (2016). Sistem Informasi Pengolahan Data Penduduk Nagari Tanjung Lolo, Kecamatan Tanjung Gadang, Kabupaten Sijunjung Berbasis Web. Jurnal Edik Informatika, 2(2), 163-170

Asynuzar, N. (2014). Pengembangan Aplikasi Pengolahan Data Cuaca Pada Stasiun Meteorologi Maritim Pontianak. Jurnal Sistem dan Teknologi Informasi (JustIN), 3(1)

Fajri, A. F., \& Iswandy, E. (2017). Sistem Informasi Pengolahan Data Laporan Statistik Pertanian Tanaman Pangan Studi Kasus (Koto Gadih) Payakumbuh. Jurnal Sains dan Informatika,Kopertis X, 53-60

Hamzah, H. (2016). Sistem Pengolahan Data Kegiatan Penelitian dan Pengabdian Kepada Masyarakat di Universitas Respati Yogyakarta. Scientific Journal of Informatics, 3(1), 1-10

Khambali, M., Rohayah, S., \& Somantri, O. (2017). Pembangunan Aplikasi Pengolahan Data Unsur Cuaca Pada Statiun Meteorologi Kota Tegal Dengan Model Waterfall. Jurnal Informatika:Jurnal pengembangan IT(JPIT), 2(1), 3741

Lestari, S. (2015). Analisis dan Perancangan Sistem Informasi Pengolahan Data Penduduk di Kantor Kecamatan Sungai Selan Bangka Tengah. Jurnal SIFOM

Musliani, W, L., \& Mawarni, S. (2017). Aplikasi Pengolahan Data Posyandu. Jurnal INOVTEK POLBENG: Seri Informatika, 2(1), 41-47
Tiningsih, E. W. T. (2011). Sistem Informasi Pengolahan Data Perpustakaan Pada SMK Negeri 1 Demak. Jurnal Teknik-Unisfat, 6(2), 89-102 